\title{
Comparison of the Oncological Outcomes of Stenting as a Bridge to Surgery and Surgery Alone in Stages II-III Obstructive Colorectal Cancer; A Retrospective Study
}

Hiroaki Uehara ( $\nabla$ hiroaki.u@hotmail.co.jp)

Niigata City General Hospital: Niigata Shimin Byoin https://orcid.org/0000-0001-6037-6526

Toshiyuki Yamazaki

Niigata City General Hospital: Niigata Shimin Byoin

Akira Iwaya

Niigata City General Hospital: Niigata Shimin Byoin Hitoshi Kameyama

Niigata City General Hospital: Niigata Shimin Byoin

Rina Harada

Niigata City General Hospital: Niigata Shimin Byoin

Masaru Komatsu

Niigata City General Hospital: Niigata Shimin Byoin

Motoharu Hirai

Niigata City General Hospital: Niigata Shimin Byoin

Akira Kubota

Niigata City General Hospital: Niigata Shimin Byoin

Tomohiro Katada

Niigata City General Hospital: Niigata Shimin Byoin

Kazuaki Kobayashi

Niigata City General Hospital: Niigata Shimin Byoin

Munehiro Sato

Niigata City General Hospital: Niigata Shimin Byoin

Daisuke Sato

Niigata City General Hospital: Niigata Shimin Byoin Naoyuki Yokoyama

Niigata City General Hospital: Niigata Shimin Byoin Shirou Kuwabara

Niigata City General Hospital: Niigata Shimin Byoin

Tetsuya Otani

Niigata City General Hospital: Niigata Shimin Byoin 


\section{Research article}

Keywords: obstructive colorectal cancer, stent, bridge to surgery, retrospective study, distant metastatic recurrence

Posted Date: October 6th, 2020

DOl: https://doi.org/10.21203/rs.3.rs-73129/v1

License: (c) (i) This work is licensed under a Creative Commons Attribution 4.0 International License. Read Full License

Version of Record: A version of this preprint was published at Annals of Coloproctology on July 13th, 2021. See the published version at https://doi.org/10.3393/ac.2020.01067.0152. 


\section{Abstract}

\section{Background:}

The Japanese Society for Cancer of the Colon and Rectum guidelines in 2019, stated that stenting as a bridge to surgery (BTS) for obstructive cancer may cause perforation and other adverse effects, which may worsen the long-term prognosis. This study aimed to evaluate retrospectively the surgical and oncological outcomes of BTS using a stent compared with surgery alone for obstructive colorectal cancer.

\section{Methods:}

Consecutive patients who underwent curative resection for stages II-III obstructive colorectal cancer at our institution from January 2009 to March 2020, were registered retrospectively and divided into 43 patients in the BTS group and 65 patients in the surgery alone group. We compared the surgical and oncological outcomes between the two groups.

\section{Results:}

Stent-related perforation did not occur in any patient. The patient in whom the stent placement was unsuccessful underwent emergency surgery with poor decompression even after SEMS placement (clinical success rate, 97.4\%). The pathological characteristics were not significantly different between the groups. The following surgical outcomes in the BTS group were superior to those in the surgery alone group: non-emergency surgery $(P<0.001)$, surgical approach $(P=0.006)$, and length of hospital stay $(P=$ 0.020). The median follow-up time was 44.9 months (range, $1.1-126.5$ months). The 3-year relapse-free survival rates were $68.4 \%$ and $58.2 \%(P=0.411)$, and the overall survival rates were $78.3 \%$ and $88.2 \%(P=$ $0.255)$ in the surgery alone and BTS groups, respectively. The 3-year locoregional recurrence rates were $10.2 \%$ and $8.0 \%(P=0.948)$, and distant metastatic recurrence rates were $13.3 \%$ and $30.4 \%(P=0.035)$ in the surgery alone and BTS groups, respectively.

\section{Conclusion:}

This study revealed that BTS with stent may be associated with a higher frequency of distant metastatic recurrence. Stent for stages II-III obstructive colorectal cancer potentially worsens oncological outcomes.

\section{Trial registration:}

This study was registered retrospectively in University hospital Medical Information Network (UMIN)Clinical Trials Registry. (Trial registration: UMIN, UMIN000040771. Registered 15 June 2020 Retrospectively registered, https://upload.umin.ac.jp/cgi-open-bin/icdr/ctr_view.cgi? recptno=R000046558).

\section{Background}


It has been reported that $8-16 \%$ of colorectal cancer patients develop bowel obstruction and require an emergency procedure to correct this issue [1-3]. Although patients with obstructive colorectal cancer generally undergo some type of emergency procedure, emergency surgery is associated with higher rates of mortality and morbidity compared with elective surgery [4]. In order to overcome this issue, a bridge to surgery (BTS) using stent for obstructive colorectal cancer was proposed. BTS using stent enables an elective resection in patients to potentially to avoid use of a stoma.

Initial systematic reviews have revealed a higher rate of laparoscopic surgery after stent placement, with lower morbidity rates, fewer temporary stoma creations, and higher primary anastomosis rates $[5,6]$. Despite the short-term benefit of stent, stenting procedures might be associated with a higher rate of perineural invasion, increased potential for tumor cell dissemination, and increased risk of recurrence due to perforations associated with the stent or guidewire [7-10]. In a comparative study, Sabbagh et al. used a propensity score analysis and found that BTS with stent was associated with worse overall survival compared with immediate surgery [11]. In 2019, the Japanese Society for Cancer of the Colon and Rectum (JSCCR) guidelines stated that obstruction relief by stent treatment as part of a BTS premised on curative surgical removal may also cause perforation and other adverse effects, which may worsen the

long-term prognosis [12]. However, this has not been confirmed by recent meta-analyses [13]. In 2020, the European Society of Gastrointestinal Endoscopy guidelines recommended that stenting as a BTS be discussed as part of a shared decision-making process as a treatment option in patients with potentially curable left-sided obstructing colon cancer as an alternative to emergency resection [14]. we speculated that the locoregional recurrence rate would be worse in the BTS group compared with the surgery alone group.

To reveal the oncological outcome of stenting as a BTS for curable obstructive colorectal cancer, we hypothesed that the recurrence rate would be worse in the BTS group compared with the surgery alone group, and designed this retrospective cohort study at our institution.

\section{Methods}

We retrospectively evaluated and compared the surgical and oncological outcomes of BTS with stent for obstructive colorectal cancer and those of surgery alone. Consecutive patients who underwent curative resection for stages II-III obstructive colorectal cancer at Niigata City General Hospital were divided into the BTS group (treated from April 2012, when self-expandable metallic stent for malignant bowel obstruction was covered by insurance in Japan, to March 2020) and the surgery alone group (treated from January 2008 to March 2020). The surgery alone group included patients who did not undergo decompression and patients who underwent non-surgical bowel decompression at the oral side of obstructive colorectal cancer and had a nasal ileus tube, nasogastric tube, or trans-anal decompression tube placed before curative resection. The patients who underwent preoperative bowel decompression procedures by stoma creation at the oral side of the cancer were excluded. In this study, obstructive colorectal cancer was diagnosed by computed tomography (CT) and colonoscopy in which urgent decompression was deemed necessary. 
In Japan, the indications for stent placement in cases of obstructive colorectal cancer are generally based on the ColoRectal Obstruction Scoring System (CROSS). The CROSS system was developed in 2012 by the Japan Colonic Stent Safe Procedure Research Group as a generally applicable technique for the assessment of colonic obstruction and stenosis; the CROSS system is published on the Research Group's home page (http://colon-stent.com/: Table 1). The colonic stents used in BTS for patients with CROSS scores between 0 and 1, and those used for palliative reasons in patients with scores between 0 and 3 are indicated appropriately [15]. At our institute, the indications for stent placement in each case of obstructive colorectal cancer were finally decided based on the CROSS scores, but the decisions were made not by surgeons but by gastroenterologists. Regarding stent placement, we treated malignant large bowel obstruction with either the WallFlexTM Colonic Stent (Boston Scientific Corp.), HANAROSTENT NaturfitTM (Boston Scientific Corp.), or the Niti-STM (TaeWoong Corp.). All procedures for stent placement were performed by a gastroenterologist.

Table 1

The ColoRectal Obstruction Scoring System (CROSS).

\begin{tabular}{|lc|}
\hline Level of oral intake & Score \\
\hline Requiring continuous decompressive procedure & 0 \\
\hline No oral intake & 1 \\
\hline Liquid or enteral nutrient & 2 \\
\hline Soft solids, low-residue, and full diet with symptoms of stricture & 3 \\
\hline Soft solids, low-residue, and full diet without symptoms of stricture* & 4 \\
\hline $\begin{array}{l}\text { * Symptoms of stricture contain abdominal pain/cramps, abdominal distension, nausea, vomiting, } \\
\text { constipation, and diarrhea which are related to gastrointestinal transit. }\end{array}$ \\
\hline
\end{tabular}

Follow-up was performed according to the 2019 JSCCR guidelines for the treatment of colorectal cancer [12] and included outpatient visits at 3-month intervals during the first 3 years and visits at 6-month intervals thereafter until 5 years after curative resection; at a minimum, carcinoembryonic antigen (CEA) levels were measured at each visit. Abdominal (liver) ultrasonography or CT was recommended every 6 months for the first 3 years after resection and yearly thereafter. In addition, surveillance colonoscopy was performed at 1,3 , and 5 years after curative resection.

The duration of decompression was defined as the time that elapsed between the non-surgical bowel decompression procedures and curative resection. Postoperative complications were defined according to the Clavien-Dindo classification system. In this study, locoregional recurrence was defined as recurrence in the anastomosis, regional lymph nodes, or peritoneum.

\section{Statistical analysis}


Continuous variables are expressed as medians (range). The Mann-Whitney $\mathrm{U}$ test was used to compare continuous variables, and chi-square or Fisher's exact tests were used to compare discrete variables. The Kaplan-Meier method and the log-rank test were used to compare the survival curves between groups. A comparison of recurrent probabilities was performed using a Cox proportional hazards model. All analyses were two-sided, and $P$ values less than 0.05 were considered statistically significant. All statistical analyses were performed with EZR (Saitama Medical Center, Jichi Medical University, Saitama, Japan), which is a graphical user interface for $\mathrm{R}$ (The R Foundation for Statistical Computing, Vienna, Austria); more precisely, EZR is a modified version of R commander that is designed to add statistical functions that are frequently used in biostatistics.

\section{Results}

\section{Patient characteristics}

The patient characteristics are shown in Table 2. In all, 108 patients were retrospectively evaluated. The surgery alone group contained 65 patients, while the BTS group contained 43 patients. The median ages were 72 years (range, 31-92 years) in the surgery alone group and 69 years (range, 39-90 years) in the BTS group. Of the 65 patients in the surgery alone group, 58 (89.2\%) had a CROSS score between 0 and 2, while of the 43 patients in the BTS group, $35(81.4 \%)$ had a CROSS score between 0 and $2(P=0.269)$. Twenty-three (35.4\%) of 65 patients in the surgery alone group required preoperative non-surgical bowel decompression while all 43 patients (100\%) in the BTS group required bowel decompression, which was accomplished by the stent placement $(P<0.001)$. The duration of the non-surgical bowel decompression procedure before curative resection in the BTS group was significantly longer than that in the surgery alone group ( 9 days (range, $0-30$ days) vs. 18 days (range, $10-67$ days); $P<0.001$ ). In terms of tumor location, 25 (38.5\%) of 65 patients had right-sided colorectal cancer in the surgery alone group, while 12 $(27.9 \%)$ of 43 patients in the BTS group had right-sided cancer. However, this difference was not statistically significant $(P=0.304)$. The pathological characteristics (e.g., tumor size, TNM category, histological type, venous invasion, and lymphatic invasion) were not significantly different between the two groups. 
Table 2

Patient characteristics.

\begin{tabular}{|c|c|c|c|c|}
\hline & & $\begin{array}{l}\text { Surgery } \\
\text { alone } \\
(\mathrm{N}=65)\end{array}$ & $\begin{array}{l}\text { BTS } \\
(N=43)\end{array}$ & $\begin{array}{l}P \\
\text { value }\end{array}$ \\
\hline \multirow[t]{2}{*}{ Gender (\%) } & Male & $42(64.6)$ & $24(55.8)$ & 0.422 \\
\hline & Female & $23(35.4)$ & $19(44.2)$ & \\
\hline Age (range) & & $\begin{array}{l}72(31- \\
92)\end{array}$ & $\begin{array}{l}69(39- \\
90)\end{array}$ & 0.466 \\
\hline $\mathrm{BMI}, \mathrm{kg} / \mathrm{m}^{2}$ (range) & & $\begin{array}{l}21.5 \\
(13.7- \\
29.4)\end{array}$ & $\begin{array}{l}20.3 \\
(14.6- \\
28.4)\end{array}$ & 0.496 \\
\hline \multirow[t]{2}{*}{ ASA-PS, class (\%) } & 1 & $21(32.3)$ & $12(27.9)$ & 0.674 \\
\hline & 2,3 & $44(67.7)$ & $31(72.1)$ & \\
\hline \multirow[t]{2}{*}{ The score of CROSS (\%) } & $0-2$ & $58(89.2)$ & $35(81.4)$ & 0.269 \\
\hline & 3,4 & $7(10.8)$ & $8(18.6)$ & \\
\hline $\begin{array}{l}\text { Bowel decompression" } \\
(\%)\end{array}$ & & $23(35.4)$ & $43(100)$ & $<.001 *$ \\
\hline $\begin{array}{l}\text { Duration of } \\
\text { decompression§, days } \\
\text { (range) }\end{array}$ & & $9(0-30)$ & $\begin{array}{l}18(10- \\
67)\end{array}$ & $<.001 *$ \\
\hline \multirow[t]{3}{*}{ Types of stent (\%) } & WallFlex ${ }^{\mathrm{TM}}$ & - & $16(37.2)$ & - \\
\hline & HANAROSTENT Naturfit ${ }^{\mathrm{TM}}$ & - & $7(16.3)$ & \\
\hline & Niti-S ${ }^{T M}$ & - & $20(46.5)$ & \\
\hline \multirow[t]{2}{*}{ Tumor location (\%) } & Left-sided & $40(61.5)$ & $31(72.1)$ & 0.304 \\
\hline & Right-sided & $25(38.5)$ & $12(27.9)$ & \\
\hline
\end{tabular}

\# Bowel decompression was defined as non-surgical procedures by a nasal ileus tube, nasogastric tube or colonic stent.

§Duration of decompression was defined as duration performing non-surgical bowel decompression procedures to curative resection.

* The values were statistically significant.

BTS: bridge to surgery, BMI: Body mass index, ASA-PS: American Society of Anesthesiologistsphysical status classification, CEA: Carcinomaembryonic antigen, CROSS: The ColoRectal Obstruction Scoring System 


\begin{tabular}{|c|c|c|c|c|}
\hline & & $\begin{array}{l}\text { Surgery } \\
\text { alone } \\
(\mathrm{N}=65)\end{array}$ & $\begin{array}{l}\text { BTS } \\
(\mathrm{N}=43)\end{array}$ & $\begin{array}{l}P \\
\text { value }\end{array}$ \\
\hline \multicolumn{2}{|l|}{ Tumor size, cm (range) } & $\begin{array}{l}5.5(2.5- \\
13.5)\end{array}$ & $\begin{array}{l}5.6(3.5- \\
10.5)\end{array}$ & 0.975 \\
\hline \multirow[t]{2}{*}{ pT category (\%) } & pT2-3 & $49(75.4)$ & $27(62.8)$ & 0.198 \\
\hline & pT4 & $16(24.6)$ & $16(37.2)$ & \\
\hline \multirow[t]{2}{*}{ pN category $(\%)$} & pNO & $38(58.5)$ & $28(65.1)$ & 0.548 \\
\hline & $\mathrm{pN} 1,2$ & $27(41.5)$ & $15(34.9)$ & \\
\hline \multirow[t]{2}{*}{ Histological type (\%) } & $\begin{array}{l}\text { Well or moderately differentiated } \\
\text { tubular adenocarcinoma }\end{array}$ & $60(92.3)$ & $43(100)$ & 0.155 \\
\hline & Others & $5(7.7)$ & $0(0)$ & \\
\hline \multirow[t]{2}{*}{ Venous invasion (\%) } & V0 & $26(40.0)$ & $14(32.6)$ & 0.542 \\
\hline & $\mathrm{V} 1,2$ & $39(60.0)$ & $29(67.4)$ & \\
\hline \multirow[t]{2}{*}{ Lymphatic invasion (\%) } & Ly0 & $40(61.5)$ & $32(74.4)$ & 0.212 \\
\hline & Ly 1,2 & $25(38.5)$ & $11(25.6)$ & \\
\hline \multicolumn{5}{|c|}{$\begin{array}{l}\text { \# Bowel decompression was defined as non-surgical procedures by a nasal ileus tube, nasogastric } \\
\text { tube or colonic stent. }\end{array}$} \\
\hline \multicolumn{5}{|c|}{$\begin{array}{l}\text { §Duration of decompression was defined as duration performing non-surgical bowel decompression } \\
\text { procedures to curative resection. }\end{array}$} \\
\hline \multicolumn{5}{|c|}{ * The values were statistically significant. } \\
\hline \multicolumn{5}{|c|}{$\begin{array}{l}\text { BTS: bridge to surgery, BMI: Body mass index, ASA-PS: American Society of Anesthesiologists- } \\
\text { physical status classification, CEA: Carcinomaembryonic antigen, CROSS: The ColoRectal Obstruction } \\
\text { Scoring System }\end{array}$} \\
\hline
\end{tabular}

All stent placement procedures except one were clinically successful. The patient in whom the placement was unsuccessful underwent emergency surgery with poor decompression even after stent placement (clinical success rate, $97.7 \%$ ). Stent-related perforations according to the pathological findings did not occur in any patients in the BTS group (stent-related perforation rate, $0 \%$ ).

\section{Surgical outcomes}

The surgical outcomes are shown in Table 3. One (2.3\%) of the 43 patients in the BTS group required emergency surgery, which was significantly fewer than the $19(29.2 \%)$ of 65 patients in the surgery alone group $(P<0.001)$. In terms of the surgical approach used for curative resection, the number of patients in the BTS group who underwent laparoscopic surgery was significantly higher than that in the surgery alone group $(P=0.006)$. Two $(4.7 \%)$ of 43 patients in the BTS group and $11(16.9 \%)$ of 65 patients in the 
surgery alone group required a stoma during curative surgery $(P=0.072)$. Operative time in the surgery alone group was significantly shorter than that in the BTS group (187 min (range, $109-596 \mathrm{~min}$ ) vs. $228 \mathrm{~min}$ (range, 138-343 min); $P<0.001$ ). No significant differences were observed in the number of postoperative days until flatus, stool discharge, or oral intake of food and water between the surgery alone group and the BTS group. The average length of postoperative hospital stay in the BTS group was two days shorter than that in the surgery alone group (11 days (range, 6-64 days) vs. 9 days (range, 630 days); $P=0.020$ ). Postoperative complications higher than grade 2 according to the Clavien-Dindo classification system occurred in $3(4.6 \%)$ of 65 patients in the surgery alone group and in $4(9.3 \%)$ of 43 patients in the BTS group, but this difference was not significant $(P=0.375)$. 
Table 3

Surgical outcomes.

\begin{tabular}{|c|c|c|c|c|}
\hline & & $\begin{array}{l}\text { Surgery } \\
\text { alone } \\
(N=65)\end{array}$ & $\begin{array}{l}\text { BTS } \\
(\mathrm{N}=43)\end{array}$ & $\begin{array}{l}P \\
\text { value }\end{array}$ \\
\hline Emergency surgery (\%) & & $19(29.2)$ & $1(2.3)$ & $\begin{array}{l}< \\
0.001 *\end{array}$ \\
\hline \multirow[t]{2}{*}{ Surgical approach (\%) } & Open & $41(63.1)$ & $15(34.9)$ & $0.006 *$ \\
\hline & Laparoscopic & $24(36.9)$ & $28(65.1)$ & \\
\hline Stoma creation during curative resection (\%) & & $11(16.9)$ & $2(4.7)$ & 0.072 \\
\hline Number of dissection lymph nodes (range) & & $\begin{array}{l}21(3- \\
113)\end{array}$ & $\begin{array}{l}25(8- \\
57)\end{array}$ & 0.418 \\
\hline \multirow[t]{3}{*}{ Resection status of lymph node (\%) } & D1 & $6(9.2)$ & $0(0)$ & 0.12 \\
\hline & D2 & $15(23.1)$ & $9(20.9)$ & \\
\hline & D3 & $44(67.7)$ & $34(79.1)$ & \\
\hline Operative time, minutes (range) & & $\begin{array}{l}187 \\
(109- \\
596)\end{array}$ & $\begin{array}{l}228 \\
(138- \\
343)\end{array}$ & $<.001^{\#}$ \\
\hline Blood loss, g (range) & & $\begin{array}{l}80(0- \\
3110)\end{array}$ & $\begin{array}{l}10(5- \\
1430)\end{array}$ & 0.362 \\
\hline $\begin{array}{l}\text { Postoperative days until gas or stool discharge, } \\
\text { days (range) }\end{array}$ & & $2(0-9)$ & $2(0-18)$ & 0.736 \\
\hline $\begin{array}{l}\text { Postoperative days until oral intake starting, } \\
\text { days (range) }\end{array}$ & & $4(2-18)$ & $4(3-20)$ & 0.918 \\
\hline $\begin{array}{l}\text { Length of postoperative hospital stay, days } \\
\text { (range) }\end{array}$ & & $11(6-64)$ & $9(6-30)$ & $0.020^{\#}$ \\
\hline Postoperative complications (\%) & & $18(27.7)$ & $11(25.6)$ & 1 \\
\hline \multirow[t]{2}{*}{$\begin{array}{l}\text { Postoperative complications (Clavien-Dindo } \\
\text { Classification) (\%) }\end{array}$} & $1-2$ & $15(23.1)$ & $7(16.3)$ & 0.375 \\
\hline & $3-5$ & $3(4.6)$ & $4(9.3)$ & \\
\hline \multicolumn{5}{|l|}{ * The values were statistically significant. } \\
\hline BTS: bridge to surgery & & & & \\
\hline
\end{tabular}

\section{Characteristics of adjuvant chemotherapies}

The characteristics of adjuvant chemotherapies used are shown in Table 4. The JSCCR guidelines recommended adjuvant chemotherapy in patients with high-risk stage II or stage III cancer [12]. For 
adjuvant chemotherapy, either oral 5-FU/LV, oral 5-FU, Capecitabine, mFOLFOX6, CapeOX, or SOX was selected in accordance with the patient's condition. In all, 38 (58.5\%) of 65 patients in the surgery alone group and 20 (46.5\%) of 43 patients in the BTS group received any of the above regimens as adjuvant chemotherapy for 6 months.

Table 4

Characteristics of adjuvant chemotherapy

\begin{tabular}{|c|c|c|c|c|}
\hline & & $\begin{array}{l}\text { Surgery alone } \\
(\mathrm{N}=65)\end{array}$ & $\begin{array}{l}\text { BTS } \\
(\mathrm{N}=43)\end{array}$ & $P$ value \\
\hline \multirow[t]{7}{*}{ Adjuvant chemotherapy (\%) } & Performing cases & $38(58.5)$ & $20(46.5)$ & 0.517 \\
\hline & Oral 5-FU/LV or 5-FU & $16(24.6)$ & $12(27.9)$ & \\
\hline & $5-\mathrm{FU}$ & $1(1.5)$ & $0(0)$ & \\
\hline & Capecitabine & $5(7.7)$ & $7(16.3)$ & \\
\hline & mFOLFOX6 & $2(3.1)$ & $0(0)$ & \\
\hline & sox & $1(1.5)$ & $1(2.3)$ & \\
\hline & CapeOX & $2(3.1)$ & $7(7.0)$ & \\
\hline
\end{tabular}

\section{Oncological outcomes}

The median follow-up time in the surgery alone group and the BTS group was 49.4 months (range, 1.1126.5 months) and 37.8 months (range, 2.6-80.1 months), respectively. This difference was not statistically significant $(P=0.079)$. The 3-year relapse-free survival rates were $68.4 \%$ and $58.2 \%(P=$ $0.411)$, while the 3-year overall survival rates were $78.3 \%$ and $88.2 \%(P=0.255)$ for the surgery alone and BTS groups, respectively (Fig. 1a, b). The 3-year locoregional recurrence rates were $10.2 \%$ and $8.0 \%$ in the surgery alone and BTS groups, respectively $(P=0.948)(F i g .2 a)$, while the 3-year distant metastatic recurrence rates were $13.3 \%$ and $30.4 \%$ in the surgery alone and BTS groups, respectively $(P=0.035)$ (Fig. 2b).

The Cox proportional hazards model analysis for recurrence in Table 5 showed no significant difference in any recurrences (HR 2.22, 95\% confidence interval $(\mathrm{Cl}) 0.95-5.19 \mathrm{P}=0.066)$ and locoregional recurrences (HR 1.05, 95\% Cl 0.26-4.29; $\mathrm{P}=0.948)$, whereas a significant difference between treatment groups was found for distant metastatic recurrences (HR 2.67, 95\% $\mathrm{Cl} 1.03-6.91 ; \mathrm{P}=0.043$ ). Specifically, the number of patients in the BTS group who had liver recurrence was higher than that in the surgery alone group. 
Table 5

Oncological outcomes for recurrence.

\begin{tabular}{|c|c|c|c|c|}
\hline & $\begin{array}{l}\text { Surgery alone } \\
(\mathrm{N}=65)\end{array}$ & $\begin{array}{l}\text { BTS } \\
(\mathrm{N}=43)\end{array}$ & Hazard ratio\# & $P$ value \\
\hline Any recurrences (\%) & $10(15.4)$ & $12(27.9)$ & $2.22(0.95,5.19)$ & 0.066 \\
\hline Locoregional recurrences (\%) & $6(9.2)$ & $3(7.0)$ & $1.05(0.26,4.29)$ & 0.948 \\
\hline Anastomotic & $0(0)$ & $1(2.3)$ & & \\
\hline Peritoneum & $5(7.7)$ & $3(7.0)$ & & \\
\hline Pelvic lymph node & $1(1.5)$ & $0(0)$ & & \\
\hline Distant metastatic recurrences (\%) & $7(10.8)$ & $11(25.6)$ & $2.67(1.03,6.91)$ & $0.043^{\star}$ \\
\hline Liver & $1(1.5)$ & $6(14.0)$ & & \\
\hline Lung & $3(4.6)$ & $3(7.0)$ & & \\
\hline Para-aortic lymph node & $2(3.1)$ & $1(2.3)$ & & \\
\hline Ovary & $1(1.5)$ & $1(2.3)$ & & \\
\hline \multicolumn{5}{|c|}{$\begin{array}{l}\text { \# The values were determined by Cox proportional hazards model analysis and those in parentheses } \\
\text { were } 95 \text { per cent confidence intervals. Surgery alone was reference group. }\end{array}$} \\
\hline \multicolumn{5}{|c|}{ * The values were statistically significant. } \\
\hline BTS: bridge to surgery & & & & \\
\hline
\end{tabular}

\section{Discussion}

In this study, BTS using with stent in patients who presented with obstructive colorectal cancer was associated with better surgical outcomes. In a comparison of the surgery alone group and the BTS group, significant differences were found in the avoidance of emergency surgery, the presence of large wounds due to open surgery, and length of hospital stay. The median operative time was longer in the BTS group than in the surgery alone group $(P<0.001)$. We reasoned that the BTS group had a higher rate of laparoscopic surgery compared to the surgery alone group. The better surgical outcomes in the BTS group might lead to an improvement in the postoperative quality of life. However, in the present study, BTS using stent for obstructive colorectal cancer with curative potential was associated with impaired mid-term oncological outcomes. When the two groups were compared, no significant differences were found in relapse-free survival, overall survival, and locoregional recurrence rates, but in contrast, a significant difference was found in distant recurrence.

A meta-analysis by Ceresoli et al. in 2017 reported that stents such as BTS had no adverse effects on the 3-year or 5-year mortality rates or on local recurrence [16]. Recently, 2 meta-analyses revealed no 
significant difference between the stent group and the emergency surgery group in terms of overall survival, disease-free survival, and recurrence $[13,17]$. In 2016, the multicenter, randomized controlled ESCO trial reported no difference in the 3-year overall survival and progression-free survival rates between the colonic stenting (BTS group) and the emergency surgery group [18].

When we designed this study, we speculated that the locoregional recurrence rate would be worse in the BTS group compared with the surgery alone group. However, in this study, the locoregional recurrence rate was not significantly different in both groups because no patients with a stent-related perforation was included in this study. If it is possible that stent-related perforations could occur in patients in the BTS group, the actual locoregional recurrence rate might be worse than that reported in this study. In 2013 , the multicenter, randomized controlled Dutch Stent-In 2 trial reported that the locoregional or distant disease recurrence rate in the stent group was worse than that in the emergency surgery group and that the disease-free survival was worse in the subgroup with stent- or guidewire-related perforations [8]. The results of the present study suggested that stent placement for curable obstructive colorectal cancer might increase the rate of distant metastases even in cases without stent- related perforations. A metaanalysis by Foo et al. in 2019 reported that a BTS stent was significantly associated with a greater chance of recurrence, especially systematic recurrence, although BTS was not associated with the 3-year disease-free survival or overall survival rate [19]. In 2013, Sabbagh et al. performed a retrospective comparative study with a propensity score analysis and found a significantly poorer overall and 5-year survival rates than patients undergoing surgery only [11]. These results suggested that stents may have an adverse effect on the long-term outcomes of colorectal cancer patients [11]. That study found a higher prevalence of synchronous distant metastasis in the stent placement group (37.5\%) than in the surgeryonly group (10.2\%) and a lower success rate (81\%) in the stent group. On the contrary, the present study limited patients to those without pathological stage IV and had a high clinical success rate (97.7\%) and a low stent-related perforation rate $(0 \%)$.

Takahashi et al. reported that stent placement increased the plasma levels of cell-free DNA and circulating tumor DNA due to tumor manipulation [20]. Maruthachalam et al. reported that stent placement increased the cytokeratin 20 mRNA level in the peripheral blood and might be associated with increased recurrence of any type [7]. In the present study, since a significant difference was observed in the distant recurrence rate, we could not deny the possibility that tumor compression by stent placement led to molecular biological effects that were associated with distant metastases. The Dutch Stent-In 2 trial reported that the liver recurrence rate was $12.5 \%$ in the stent group, which was worse than the $6.8 \%$ in the emergency surgery group [8].

These findings should be considered in several limitations. First, this study was limited by its small sample size and its retrospective, non-randomized single-institution design. Thereby, the heterogeneity of the surgical strategy may have affected the prognostic factors. Although we limited patients to those with less than pathological stage IV cancer, the patient's backgrounds were still heterogeneous. Second, the median follow-up time was relatively short, and a systematic difference was found in the observation period between the surgery alone group and the BTS group (median follow-up time was 49.4 and 37.8 
months for the surgery alone group and BTS group, respectively). Patients in the BTS group were more recently treated than those in the surgery alone group. Given the advances in chemotherapy for recurrent colorectal cancer, there might have been a trend in the BTS group that the relapse-free survival rate was worse and the overall survival rate was better compared with the surgery alone group. Lastly, although endoscopic stent placement procedures were validated, stent devices used in this study had different lengths, types, and thickness and obtained from different vendors.

\section{Conclusions}

BTS with stent seems to be an alternative procedure that can be used to avoid emergency surgery, large incisions, and a long hospital stay. Nevertheless, this study revealed that BTS with stent may be associated with a higher frequency of distant metastatic recurrence. Future research with a larger sample size and a longer observation period is warranted to confirm the findings of the present study.

\section{Abbreviations}

BTS

Bridge to surgery

JSCCR

Japanese Society for Cancer of the Colon and Rectum

CT

Computed tomography

CROSS

ColoRectal Obstruction Scoring System

CEA

Carcinoembryonic antigen

$\mathrm{Cl}$

Confidence interval

\section{Declarations}

Ethics approval and consent to participate: All procedures performed in studies involving human participants were in accordance with the ethical standards of the Institutional Research Committee and with the 1964 Helsinki Declaration and its later amendments or with comparable ethical standards. All participants have provided their written informed consent and that the study was approved by Niigata City General Hospital Ethical Committee on human research (assignment number 20-008).

Consent for publication: No applicable.

Availability of data and materials: The datasets used and analyzed during this study are available from the corresponding author upon reasonable request. 
Competing interest: The authors declare that they have no competing interest.

Funding: This study was not supported by any associations.

Authors' contributions: All authors contributed to the study conception and design. Material preparation, data collection, and analysis were performed by HU. The first draft of the manuscript was written by HU. and all authors commented on previous versions of the manuscript. TY., Al. and HK. supervised and critically reviewed the manuscript. All authors approved the final manuscript.

Acknowledgements: We would like to thank Honyaku Center Inc., a member of Japan Translation Federation (www.honyakucenter.jp) for English language editing.

\section{References}

1. Cheynel N, Cortet M, Lepage C, Benoit L, Faivre J, Bouvier AM. Trends in frequency and management of obstructing colorectal cancers in a well-defined population. Dis Colon Rectum. 2007;50:1568-75.

2. Jullumstrø E, Wibe A, Lydersen S, Edna TH. Colon cancer incidence, presentation, treatment and outcomes over 25 years. Colorectal Dis. 2011;13:512-8.

3. Winner M, Mooney SJ, Hershman DL, Feingold DL, Allendorf JD, Wright JD, Neugut Al. Incidence and predictors of bowel obstruction in elderly patients with stage IV colon cancer: a population-based cohort study. JAMA Surg. 2013;148:715-22.

4. Tekkis PP, Kinsman R, Thompson MR, Stamatakis JD. Association of Coloproctology of Great Britain, Ireland. The Association of Coloproctology of Great Britain and Ireland study of large bowel obstruction caused by colorectal cancer. Ann Surg. 2004;240:76-81.

5. Arezzo A, Passera R, Secco GL, Verra M, Bonino AM, Targarona E, Morino M. Stent as bridge to surgery for left-sided malignant colonic obstruction reduces adverse events and stoma rate compared with emergency surgery: results of a systematic review and meta-analysis of randomized controlled trials. Gastrointest Endosc. 2017;86:416-26.

6. Atukorale YN, Church JL, Hoggan BL, Lambert RS, Gurgacz SL, Goodall S, Maddern GJ. SelfExpanding Metallic Stents for the Management of Emergency Malignant Large Bowel Obstruction: a Systematic Review. J Gastrointest Surg. 2016;20:455-62.

7. Maruthachalam K, Lash GE, Shenton BK, Horgan AF. Tumour cell dissemination following endoscopic stent insertion. Br J Surg. 2007;94:1151-4.

8. Sloothaak DA, van den Berg MW, Dijkgraaf MG, Fockens P, Tanis PJ, van Hooft JE, Bemelman WA. collaborative Dutch Stent-In study group. Oncological outcome of malignant colonic obstruction in the Dutch Stent-In 2 trial. Br J Surg. 2014;101:1751-7.

9. Yamashita S, Tanemura M, Sawada G, Moon J, Shimizu Y, Yamaguchi T, Kuwai T, Urata Y, Kuraoka K, Hatanaka N, Yamashita Y, Taniyama K. Impact of endoscopic stent insertion on detection of viable circulating tumor cells from obstructive colorectal cancer. Oncol Lett. 2018;15:400-6. 
10. Kim HJ, Choi GS, Park JS, Park SY, Jun SH. Higher rate of perineural invasion in stent-laparoscopic approach in comparison to emergent open resection for obstructing left-sided colon cancer. Int J Colorectal Dis. 2013;28:407-14.

11. Sabbagh C, Browet F, Diouf M, Cosse C, Brehant O, Bartoli E, Mauvais F, Chauffert B, Dupas JL, Nguyen-Khac E, Regimbeau JM. Is stenting as "a bridge to surgery" an oncologically safe strategy for the management of acute, left-sided, malignant, colonic obstruction? A comparative study with a propensity score analysis. Ann Surg. 2013;258:107-15.

12. Hashiguchi Y, Muro K, Saito Y, Ito Y, Ajioka Y, Hamaguchi T, Hasegawa K, Hotta K, Ishida H, Ishiguro M, Ishihara S, Kanemitsu Y, Kinugasa Y, Murofushi K, Nakajima TE, Oka S, Tanaka T, Taniguchi H, Tsuji A, Uehara K, Ueno H, Yamanaka T, Yamazaki K, Yoshida M, Yoshino T, Itabashi M, Sakamaki K, Sano K, Shimada Y, Tanaka S, Uetake H, Yamaguchi S, Yamaguchi N, Kobayashi H, Matsuda K, Kotake K, Sugihara K. Japanese Society for Cancer of the Colon and Rectum. Japanese Society for Cancer of the Colon and Rectum (JSCCR) guidelines 2019 for the treatment of colorectal cancer. Int J Clin Oncol. 2020;25:1-42.

13. Cao Y, Gu J, Deng S, Li J, Wu K, Cai K. Long-term tumour outcomes of self-expanding metal stents as 'bridge to surgery' for the treatment of colorectal cancer with malignant obstruction: a systematic review and meta-analysis. Int J Colorectal Dis. 2019;34:1827-38.

14. van Hooft JE, Veld JV, Arnold D, Beets-Tan RGH, Everett S, Götz M, van Halsema EE, Hill J, Manes G, Meisner S, Rodrigues-Pinto E, Sabbagh C, Vandervoort J, Tanis PJ, Vanbiervliet G, Arezzo A. Selfexpandable metal stents for obstructing colonic and extracolonic cancer: European Society of Gastrointestinal Endoscopy (ESGE) Guideline - Update 2020. Endoscopy. 2020;52:389-407.

15. Saida Y. Current status of colonic stent for obstructive colorectal cancer in Japan; a review of the literature. J Anus Rectum Colon. 2019;3:99-105.

16. Ceresoli M, Allievi N, Coccolini F, Montori G, Fugazzola P, Pisano M, Sartelli M, Catena F, Ansaloni L. Long-term oncologic outcomes of stent as a bridge to surgery versus emergency surgery in malignant left side colonic obstructions: a meta-analysis. J Gastrointest Oncol. 2017;8:867-76.

17. Amelung FJ, Burghgraef TA, Tanis PJ, van Hooft JE, Ter Borg F, Siersema PD, Bemelman WA, Consten ECJ. Critical appraisal of oncological safety of stent as bridge to surgery in left-sided obstructing colon cancer; a systematic review and meta-analysis. Crit Rev Oncol Hematol. 2018;131:66-75.

18. Arezzo A, Balague C, Targarona E, Borghi F, Giraudo G, Ghezzo L, Arroyo A, Sola-Vera J, De Paolis P, Bossotti M, Bannone E, Forcignanò E, Bonino MA, Passera R, Morino M. Colonic stenting as a bridge to surgery versus emergency surgery for malignant colonic obstruction: results of a multicentre randomised controlled trial (ESCO trial). Surg Endosc. 2017;31:3297-305.

19. Foo CC, Poon SHT, Chiu RHY, Lam WY, Cheung LC, Law WL. Is bridge to surgery stenting a safe alternative to emergency surgery in malignant colonic obstruction: a meta-analysis of randomized control trials. Surg Endosc. 2019;33:293-302.

20. Takahashi G, Yamada T, Iwai T, Takeda K, Koizumi M, Shinji S, Uchida E. Oncological assessment of stent placement for obstructive colorectal cancer from circulating cell-free DNA and circulating tumor 
DNA dynamics. Ann Surg Oncol. 2018;25:737-44.

Figures

a Relapse-free survival

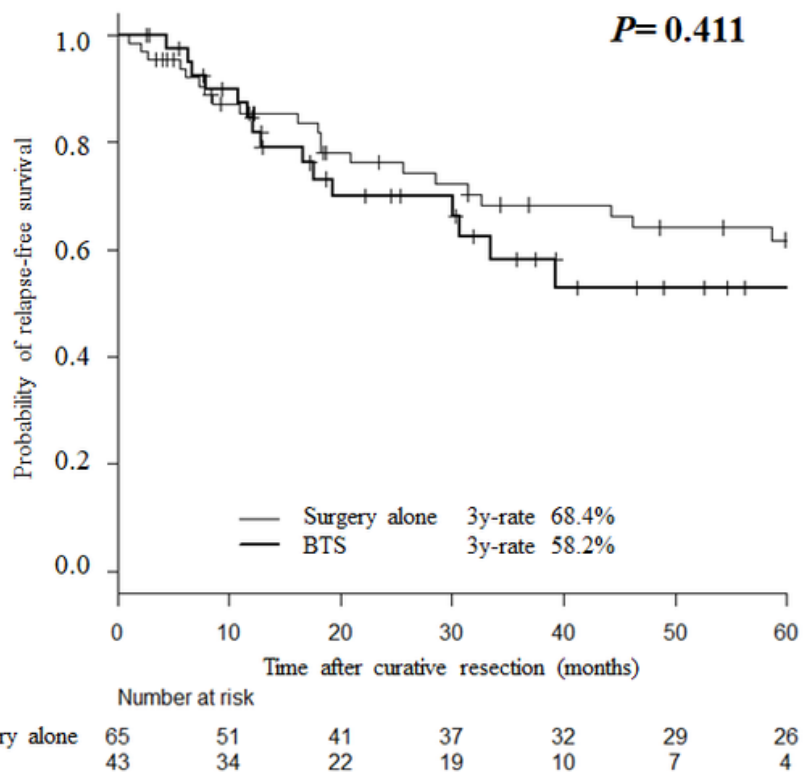

b Overall survival

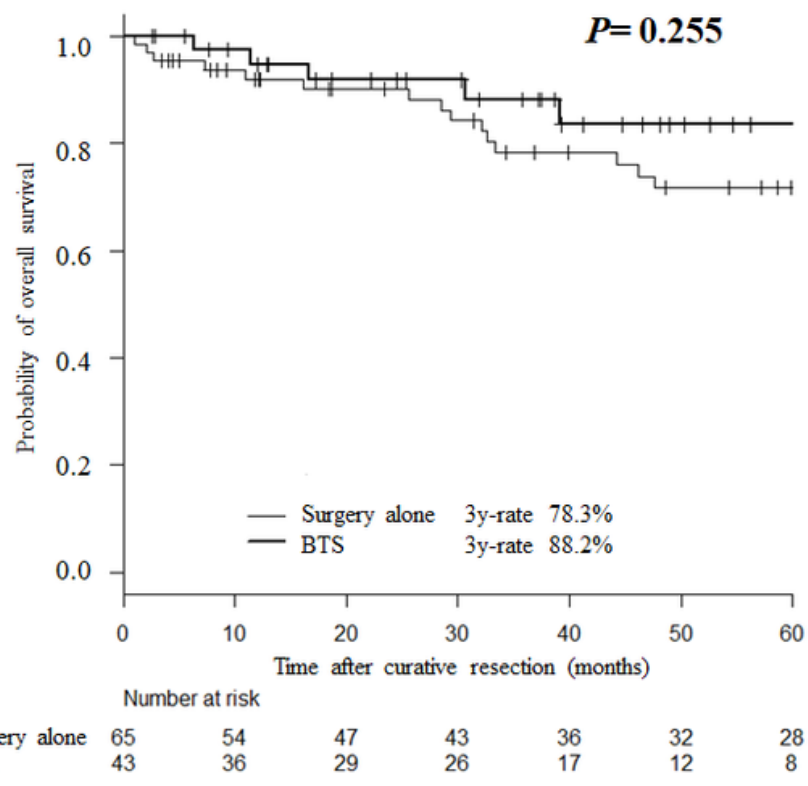

\section{Figure 1}

Kaplan-Meier survival curves of patients in the surgery alone group and the BTS group Numeric values show the 3-year relapse-free survival rates (a) and the 3-year overall survival rates (b) of the two groups 
a Locoregional recurrence rate

1.0

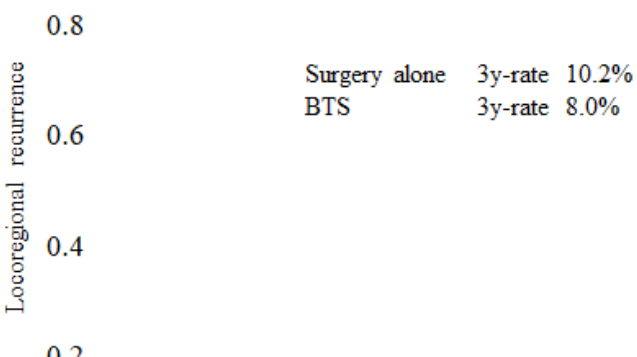

Time after curative resection (months) b Distant metastatic recurrence rate

$P=0.948$

1.0

$P=0.035$

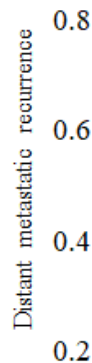

Surgery alone $3 y$-rate $13.3 \%$ BTS 3y-rate $30.4 \%$

0.6

(1)
0.0

0.2

Surgery alone

BTS
Time after curative resection (months)

Surgery alone

BTS

\section{Figure 2}

Kaplan-Meier curves of patients in the surgery alone group and BTS group Numeric values show the 3year locoregional recurrence rates (a) and the 3-year distant metastasis rates (b) of the two groups 